\title{
Aniksosaurus darwini gen. et sp. nov., a new coelurosaurian theropod from the Early Late Cretaceous of Central Patagonia, Argentina
}

\author{
Ruben D. MARTINEZ ${ }^{1}$ \& Fernando E. NOVAS ${ }^{2}$ \\ ${ }^{1}$ Laboratorio de Paleontología de Vertebrados, Universidad Nacional de la Patagonia «San Juan Bosco», \\ (9.000) Comodoro Rivadavia, Argentina. ${ }^{2}$ Laboratorio de Anatomia Comparada y Evolucion de los \\ Vertebrados, Museo Argentino de Ciencias Naturales «B. Rivadavia». CONICET. \\ Av. Angel Gallardo 470 (1405), Buenos Aires, Argentina.
}

\begin{abstract}
The theropod dinosaur Aniksosaurus darwini gen. et sp. nov. has been recovered from the Upper Cretaceous, Bajo Barreal Formation, of Central Patagonia. Aniksosaurus darwini gen. et sp. nov. was a small tetanurine, approximately 2 meters long. Aniksosaurus exhibits several unique traits (e.g., cranial cervical vertebrae with dorsoventrally deep neural arches, provided with a pair of cavities at their cranial surfaces; neural canal wide; cranial caudals with ventral sagittal keel, and transverse processes triangular-shaped in dorsal view; manual ungual phalanges robust; ilium with extremely expanded brevis shelf; femur with deep notch for M. Iliotrochantericus; metatarsal and digit IV of pes transversely narrow). Available postcranial bones of Aniksosaurus exhibit derived features of Coelurosauria (e.g., ilium with well developed cuppedicus fossa; femur with anterior trochanter proximally projected, almost reaching the level of the articular head; greater trochanter craniocaudally expanded; femoral head rectangular-shaped in cranial aspect; and fibular shaft craniocaudally narrow), as well as characteristics suggesting that the new Patagonian taxon is more derived than some basal coelurosaurians such as compsognathids, Ornitholestes, and coelurids. Comparisons with maniraptoriforms (a clade including Ornithomimosauria, Tyrannosauridae, Oviraptorosauria, Alvarezsauridae and Paraves) support that Aniksosaurus is less derived than these theropods. In sum, Aniksosaurus is here considered as a Late Cretaceous survivor of a basal coelurosaurian radiation.
\end{abstract}

Key words: coelurosaurian, Late Cretaceous, Patagonia, Argentina.

The fossil record of coelurosaurian theropods from South America has considerably increased in the last 15 years. Currently, remains of seven named species of non-avian coelurosaurians have been recovered from different Cretaceous localities of Argentina and Brazil. They are members of a variety of lineages including, among the most conspicuous, the compsognathid Mirischia asymmetrica (Naish et al., 2004), and the maniraptoriform Santanaraptor placidus (Kellner, 1999, 2001), both from the ?Albian Santana Formation of NE Brazil, the alvarezsaurids Alvarezsaurus calvoi and Patagonykus puertai (Bonaparte, 1991; Novas, 1996, 1997), possible oviraptorosaurs from NW Argentina (Frankfurt \& Chiappe, 1999), derived maniraptorans of unknown affiliation from the Maastrichtian Marilia Formation (Novas et al., 2005), and the dromaeosaurids Neuquenraptor argentinus (Novas \& Pol, 2005), Unenlagia comahuensis (Novas \& Puerta, 1997; Novas, 2003), Buitreraptor gonzalezorum (Makovicky et al., 2005), and possibly also Unquillosaurus ceibali (Novas \& Agnolín, 2004). We add to this list of coelurosaurians a new predatory dinosaur, Aniksosaurus darwini gen. et sp. nov., from the Cenomanian Bajo Barreal Formation of central Patagonia (Fig. 1).

The new taxon is known from postcranial remains belonging to at least to five specimens that were recovered from a single fossil locality. The discovery was made by personnel of the Laboratorio de Paleovertebrados of the Universidad Nacional de la Patagonia «San Juan Bosco» (UNPSJB) in the context of the project «Los vertebrados del Grupo Chubut: características y evolución-primera etapa», conducted by the senior author. The new theropod was briefly described by Martínez \& Novas (1997) who preliminarily interpreted it as a basal coelurosaurian resembling the Late Jurassic Ornitholestes hermanni from North America (Osborn, 1917; Carpenter et al., 2005).

Institutional abbreviations: AMNH, American Museum of Natural History, New York; MACN, Museo Argentino de Ciencias Naturales «B. Rivadavia», Buenos Aires; MCZ, Museum of 

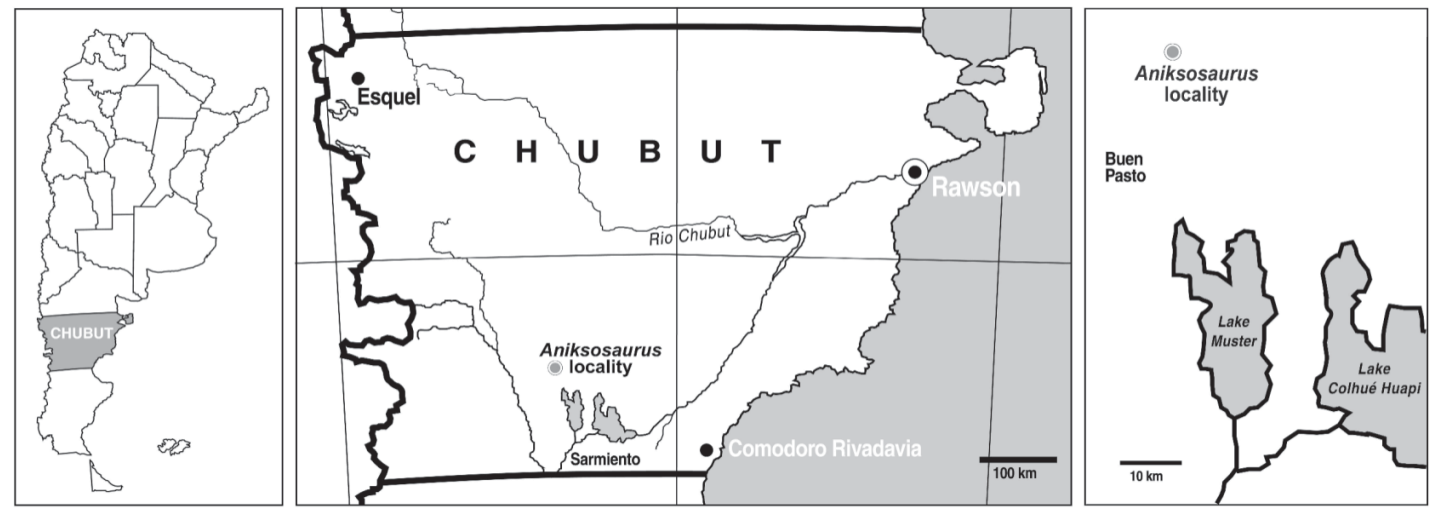

Fig. 1. Geographic location of the Estancia «Laguna Palacios», Chubut Province, central Patagonia, Argentina, where the remains of Aniksosaurus darwini gen. et sp. nov. were found.

Comparative Zoology, Cambridge; MDT-PV, Museo Desiderio Torres -Paleovertebrados, Sarmiento, Chubut, Argentina; MOR, Museum of the Rockies, Bozeman; NMC, Canadian Museum of Nature, Ottawa; YPM, Yale Peabody Museum, New Haven.

\section{MATERIALS AND METHODS}

Studied specimens: The following specimens were studied: Allosaurus fragilis (AMNH 5767), Deinonychus antirrhopus (AMNH 3015, MCZ 4371, YPM 5205, 5206, 5236), Ornitholestes hermani (AMNH 619), and Piatnitzkysaurus floresi (MACN-CH 895).

Terms of anatomical orientation: We follow terms employed in avian anatomy (Clark, 1993). «Cranial» and «caudal» are used here in place of «anterior» and «posterior», respectively.

Systematic nomenclature: Coelurosauria includes extant birds and all theropods sharing a more recent common ancestor with extant birds than with Allosaurus (Holtz et al., 2004).

Collected material of Aniksosaurus darwini: The material referred to this taxon was recovered from a single quarry four meters long, two meters wide and one meter thick. The recovered bones includes five tibiae of the right side, thus indicating that the fossil assemblage is made up, at least, by five different specimens. We interpret that they belong to a single species for the following reasons: 1) all the bones correspond to small animals of approximately the same size; 2 ) at least some bones (e.g., femur, tibia and foot of the holotype specimen, MDT-PV 1/48) were preserved in articulation; 3 ) duplicate hindlimb elements (e.g., femur, tibia, metatarsals, and pedal phalanges) are anatomically identical to the holotype; 4) available bones exhibit theropod, tetanurine and coelurosaurian synapomorphies (these derived features are listed in the text below); and, 5) there is no evidence of any other dinosaurian taxon preserved in the quarry. However, with the exception of the holotype specimen (consisting of an articulated right hindlimb), the majority of the bones were found disarticulated, thus we avoid the identification of discrete specimens composed of more than a single bone. For this reason, we confer consecutive numbers to the isolated skeletal elements found in the quarry.

The fossil-bearing tuff is pure and shows no indication of transport (J. C. Sciutto, pers. comm.). Therefore, we tentatively interpret that the taphonomic association of different individuals of Aniksosaurus darwini as evidence of gregarious behavior in this theropod species.

Interestingly, there are some differences among the various long bones of Aniksosaurus, that mainly concern the robustness of the humerus, the proportion (i.e., area and depth) of the fossa for the insertion of the M. ischiotrocantericus (Hutchinson, 2001) on the femur, and the relative size of the crista fibularis of tibia.

On femur MDT-PV1/23 there are tooth marks of small size ( $3 \mathrm{~mm}$ wide), arranged in opposing rows that were probably left by a small scavenging vertebrate.

\section{SYSTEMATIC PALEONTOLOGY \\ DINOSAURIA Owen, 1842 \\ SAURISCHIA Seeley, 1887 \\ THEROPODA Marsh, 1881 \\ TETANURAE Gauthier, 1986 \\ COELUROSAURIA Huene, 1920}

\section{Aniksosaurus, gen. nov.}

Etymology. From Greek aniksi, «spring», referring to September $21^{\text {st }}$ (i.e., the beginning of 
the spring in the Southern Hemisphere), the day when the theropod was found; and Greek saurus, «lizard».

Type species. Aniksosaurus darwini, sp. nov.

Known distribution. Upper Cretaceous, Central Patagonia, South America.

Diagnosis. As for the type and only known species.

\section{Aniksosaurus darwini, sp. nov.}

(Figs. 2-13, Table 1-2)

Holotype. MDT-PV 1/48. Articulated right hindlimb including femur, fibula, tibia and foot.

Hypodigm. Associated material collected at the site where the holotype was discovered: cervical vertebra (MDT-PV 1/14); two dorsal vertebrae (1/6, 1/18); proximal caudal vertebra (1/32); mid-caudal vertebra (1/13); six indeterminate vertebrae $(1 / 7,1 / 8,1 / 9,1 / 15,1 / 47,1 / 52)$; three indeterminate neural arches $(1 / 21,1 / 30,1 / 46)$; three left humeri $(1 / 29,1 / 37,1 / 42)$; two right humeri $(1 / 16,1 / 36)$; left ulna (1/17); manual ungual phalanx (1/40); three left ilia (1/24, 1/33, 1/ 35 ); right ilium (1/5); left ischium (1/41); two left femora $(1 / 23,1 / 26)$; two right femora $(1 / 3,1 / 27)$; three left tibiae $(1 / 1,1 / 22,1 / 34)$; four right tibiae $(1 / 2,1 / 10,1 / 28,1 / 44)$; two indeterminate metatarsi $(1 / 4,1 / 45)$; indeterminate phalanx $(1 / 43)$; and several indeterminate fragments $(1 / 11,1 / 12$, $1 / 19,1 / 20,1 / 25,1 / 31,1 / 38,1 / 39$ ).

Locality and Horizon. Laguna Palacios ranch, approximately $30 \mathrm{~km}$ north of Buen Pasto, in south-central Chubut Province, $280 \mathrm{~km}$ west of Comodoro Rivadavia, Argentina (Fig. 1). The specimens come from a level of volcanic tuff at the upper part of the Lower Member of the Bajo Barreal Formation. The Bajo Barreal Fm. is widely exposed in the southeastern corner of the Argentinian Province of Chubut, central Patagonia. The age of the Bajo Barreal Formation has recently been under dispute, although most authors agree that it falls within the Late Cretaceous. Based on palynological studies of equivalent units, Archangelsky et al. (1994) assigned a Late Albian-Cenomanian age to the Lower Bajo Barreal Fm. Recently obtained radiometric Ar-Ar dating ages from tuffs and ignimbrites of the Bajo Barreal Fm. provide ages between 91 and $95.8 \mathrm{Ma}$ (Bridge et al., 2000), a range of ages corresponding to CenomanianTuronian. This unit has yielded remains of abelisaurid theropods (e.g., Xenotarsosaurus bonapartei and other abelisaurid remains; Martínez et al., 1986; Martínez et al., 1993; Lamanna et al., 2002; Martínez et al., 2004), and a large theropod with hypertrophied pedal un- gual phalanges resembling Megaraptor namunhuaiquii (Martínez et al., 1999). Sauropods found in the same levels include remains of a diplodocimorph (Sciutto \& Martínez, 1994), a nearly complete skull and partial cervical series of a yet unnamed basal titanosaurian (Martínez, 1998b, 1999), remains referred to the basal titanosaur Andesaurus sp. (Calvo \& Bonaparte, 1991; Powell et al., 1989), most of postcranial skeleton of the early titanosaurian Epachthosaurus sciuttoi (Martínez et al., 1989, 2004; Powell, 1990), and Titanosaurinae remains (Powell, 1986; Sciutto \& Martínez, 1994). A basal igua-nodontian ornithopod, Notohypsilophodon comodorensis has also been described from the Bajo Barreal Fm (Martínez, 1998a).

Diagnosis. Small theropod with the following autapomorphies: cervical vertebrae with the neural arch pedicels unusually deep (i.e., 2.5 times the height of the centrum); wide neural canal on cervical vertebrae; cranial caudals with ventral saggital keel; manual ungual phalanges robust; iliac brevis shelf lateroventrally expanded; caudolateral surface of proximal femur with strong depression and rugosities presumably for the attachment for M. ischiotrochantericus; metatarsal IV and its correspondent digit transversely narrow.

Etymology. In honor of the great naturalist Charles Darwin, who visited Patagonia in 18321833, inspiring him to reach clearer interpretations of the evolution of life that changed human thought forever.

\section{DESCRIPTION}

Aniksosaurus was a small, albeit robust theropod with an estimated body length of 2 meters and 70 centimeters tall at the level of the pelvic girdle. Following methods explained by Heinrich et al. (1993) for estimation of body weight based on measurements from available femora, the body weight of the preserved specimens ranged between 65 through 40 kilograms (G.Casal, pers.comm.). Available specimens of Aniksosaurus appear to correspond to adult individuals, as suggested by fusion between neural arches and centra of recovered caudal vertebrae.

\section{Vertebral column and ribs}

Five incompletely preserved vertebrae (i.e., a cervical, a fragmentary dorsal, and three caudals) form the basis of the following description. Also, some fragmentary remains of ribs have been recovered. The available cervical vertebra (Fig. 2) preserves the caudal section of the neural arch and the vertebral centrum. It resembles cervical 


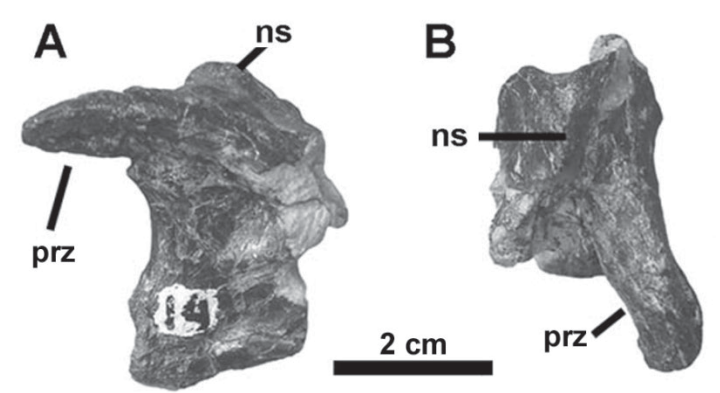

Fig. 2. Aniksosaurus darwini gen. et sp. nov. Cervical vertebra (MDT-PV 1/14) in lateral (A), and dorsal (B) views. Abbreviations: ns, neural spine; prz, prezygapophysis.

9 of Allosaurus (Madsen, 1976) and the first dorsal of Deinonychus (labeled as «cervico-dorsal» in Ostrom, 1969) in the height of the neural arch, bearing epipophyses of small size, a craniocaudally short neural spine, and presence of an excavation on the lateral surface of neural arch. The neural spine of this vertebra is incomplete, but it seems to have been craniocaudally short and dorsoventrally low. Caudal to the neural spine, a large and deep postspinal cavity is present. The postzygapophyses are robust and with lateroventrally oriented and transversely wide articular facets. The epipophyses are represented by small, elliptical rugosities on the dorsal face of the postzygapophyses. The caudal surface of the neural arch exhibits, above the neural canal, a deep pneumatic excavation. The neural canal equals the diameter of the caudal centrum surface. Such features of the cervical vertebra of Aniksosaurus differ from those of Allosaurus and Deinonychus, for example, in which the centrum is transversely wider and inversely the neural canal is smaller in size. The centrum looks proportionally reduced (in transverse diameter). It is slightly excavated laterally and lacking of ventral keel. It is internally hollow, with a thin sagital wall dividing the centrum into two internal cavities. The available cervical of Aniksosaurus differs from those of abelisauroid theropods (e.g., Ilokelesia, Laevisuchus) in that the postzygapophyses are closer to the midline than in the latter taxa (in which the neural arch is notably wider transversely), and the epipophyses are small, in contrast with the well-developed ones of abelisauroids. Finally, Aniksosaurus lacks the wide pneumatic cavities that are present caudal to the diapophysis as occurs among abelisauroid theropods (e.g., Ilokelesia).

Three caudal vertebrae have been recovered. One of them (MDT-PV 1/32; Fig. 3) resembles caudal 4 of Allosaurus (Madsen, 1976). The neural spine is high, vertically oriented and rectangular-shaped in side view and placed on the caudal half of the neural arch. Deep, but narrow preand post-spinal cavities are present at the base of the neural spine. The prezygapophyses are short and robust. The transverse processes are triangular in dorsal aspect and oriented at an angle of $40^{\circ}$ with respect to the axial plane. The centrum is amphicoelous, transversally narrow, V-shaped in cross-section, with a sharp ventral keel. Another caudal (MDT-PV 1/13, Fig. 4) resembles caudal 19 of Allosaurus (Madsen, 1976) in the proportionally long and low centrum and reduction and distal placement of the neural spine. The latter structure is craniocaudally short and the prezygapophyses slightly surpass the cranial margin of the centrum. The transverse processes are well developed and caudally projected, with their bases located on the caudal half of the neural arch. The centrum has traces of a ventral longitudinal groove.

\section{Forelimb}

Humerus. This bone (Fig.5A-C) is sigmoid in lateral view, as in Allosaurus (Madsen, 1976) and Piatnitzkysaurus (Bonaparte, 1986). Unfortunately, any of the five available humeri is complete, so the length of the most complete humerus (MDT-PV 1/16) is estimated to be around $13 \mathrm{~cm}$. The humerus is a robust element, especially towards the extremities, being subcircular in crosssection at mid-shaft. The robustness of this bone clearly distinguishes from the considerably more slender and elongate humeri of Ornitholestes and Coelurus (Carpenter et al., 2005). Albeit the extremities of the available humeri of Aniksosaurus are not entirely preserved, a «twisting» along the longitudinal axis of shaft is apparent: as observed from one of its ends, the angle resulting from the intersection of both proximal and distal transverse axes is around $50^{\circ}$, an angling similar to that of Piatnitzkysaurus floresi (MACN-CH 865). The deltopectoral crest is not complete on any of the available humeri, but the preserved portions show that it was well developed. The crest is transversely thick and cranially oriented, as usual in non-avian theropods. Its distal end is bulky and rounded. The lateral surface of the deltopectoral crest shows a weak muscle scar. The humeral shaft bears a large depression on its caudolateral surface for a muscle attachment. Another, but weaker, muscle scar extends diagonally across the caudal face of humerus, distal to the mid-shaft. The distal end of the humerus is cranially bowed; on its cranial surface there are traces of an intercondylar depression. The hu- 

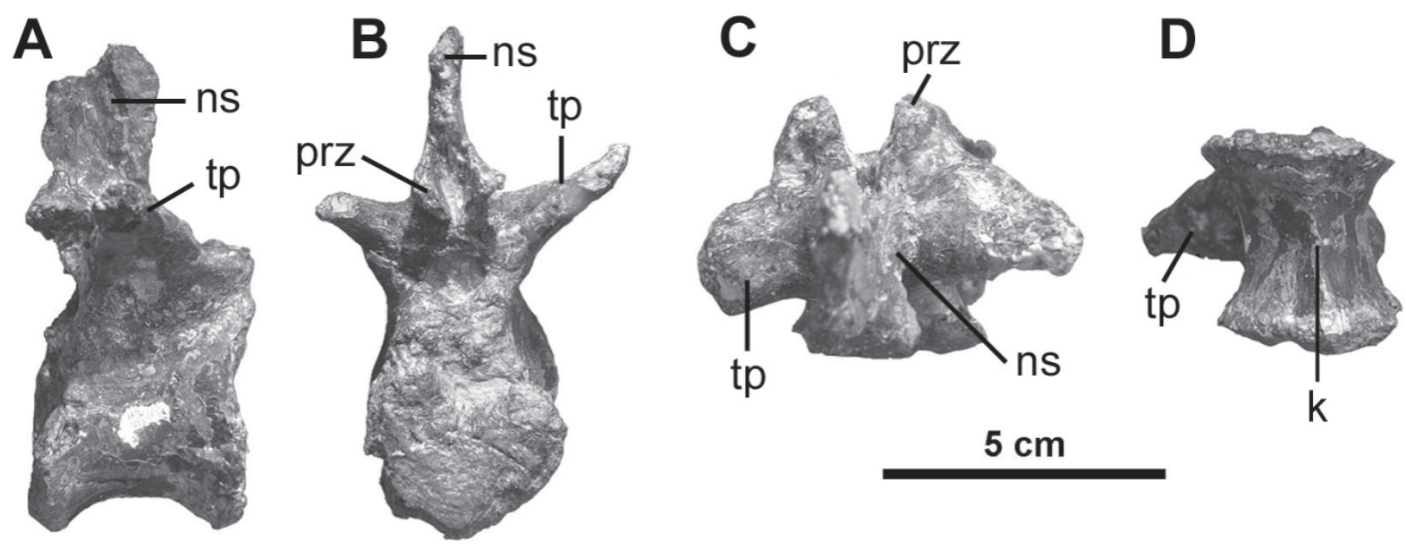

Fig. 3. Aniksosaurus darwini gen. et sp. nov. Proximal caudal vertebra in lateral (C), caudal (D), dorsal (E), and ventral (F) views. Abbreviations: k, ventral keel; ns, neural spine; prz, prezygapophysis; tp, transverse processes.

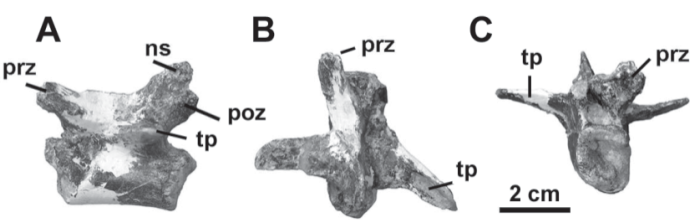

Fig. 4. Aniksosaurus darwini gen. et sp. nov. Distal caudal vertebra in lateral (A), dorsal (B) and cranial (C) views. Abbreviations: ns, neural spine; poz, postzygapophysis; prz, prezygapophysis; tp, transverse processes.

merus of Aniksosaurus is clearly distinguishable from these of abelisauroid theropods (e.g., Masiakasaurus, Carnotaurus, Aucasaurus), in which the dectopectoral crest is poorly developed and the humeral shaft is straight in both cranial and lateral views (Novas et al., 2006).

The only available ulna (MDT-PV 1/17) belongs to a left forelimb. The proximal end of the ulna is incomplete, lacking the olecranon process and the articular surface for the humerus. The ulna was found no more than $25 \mathrm{~cm}$ away from two of the available humeri (MDT-PV 1/16 and $1 / 29$ ). Although it is not unreasonable that these forelimb bones may belong to the same individual, the ulna looks proportionally elongate compared to any of the available humeri: our best estimate of the ulna to humerus length ratio is $80 \%$, a condition resembling that of the derived maniraptoran Deinonychus (Ostrom, 1969), in contrast to basal tetanurans in which the ulna is shorter with respect to the humerus. The ulna of Aniksosaurus seems more gracile than those of
Allosaurus and Piatnitzkysaurus, but it is more robust in comparisson with that of Ornitholestes and Coelurus (Carpenter et al., 2005). The ulna of Aniksosaurus is craniocaudally expanded and has a convex medial surface. The lateral tuberosity delimits the depression for articulation with the proximal end of radius. The ulnar shaft is curved (i.e., caudally convex), albeit it does not form the continuous convexity as observed in derived coelurosaurs (e.g., dromaeosaurids, troodontids), but a change in curvature exists on both proximal and distal ends, resembling basal tetanurans (e.g., Allosaurus, Piatnitzkysaurus). Notably, the caudal margin of the shaft is sharp, a condition resembling that of Megaraptor (Novas, 1998; Calvo et al., 2004), but different from the transversely rounded caudal surface seen in most theropods (e.g., Piatnitzkysaurus, Deinonychus, birds). The ulna thins distally, but expands again transversely and craniocaudally at its distalmost end. As a result, a planar surface extends across the cranial surface of the distal half of the bone. The distal articular surface of the bone is elliptical, with the longest axis transversely oriented, in contrast with the rounded distal end of coelophysids (Colbert, 1989; Raath, 1977), and the craniocaudally expanded articular surface of Allosaurus, dromaeosaurids (e.g., Saurornitholestes MOR 660) and ornithomimids. In this sense, the ulna of Aniksosaurus resembles the ulna of troodontids in its transversely expanded distal end (Troodon? NMC 12.433). Although the forearm is not well documented among basal abelisauroids, both ulna and radius are extremely short in Abelisauridae (e.g., Carnotaurus, Aucasaurus), in sharp contrast to 

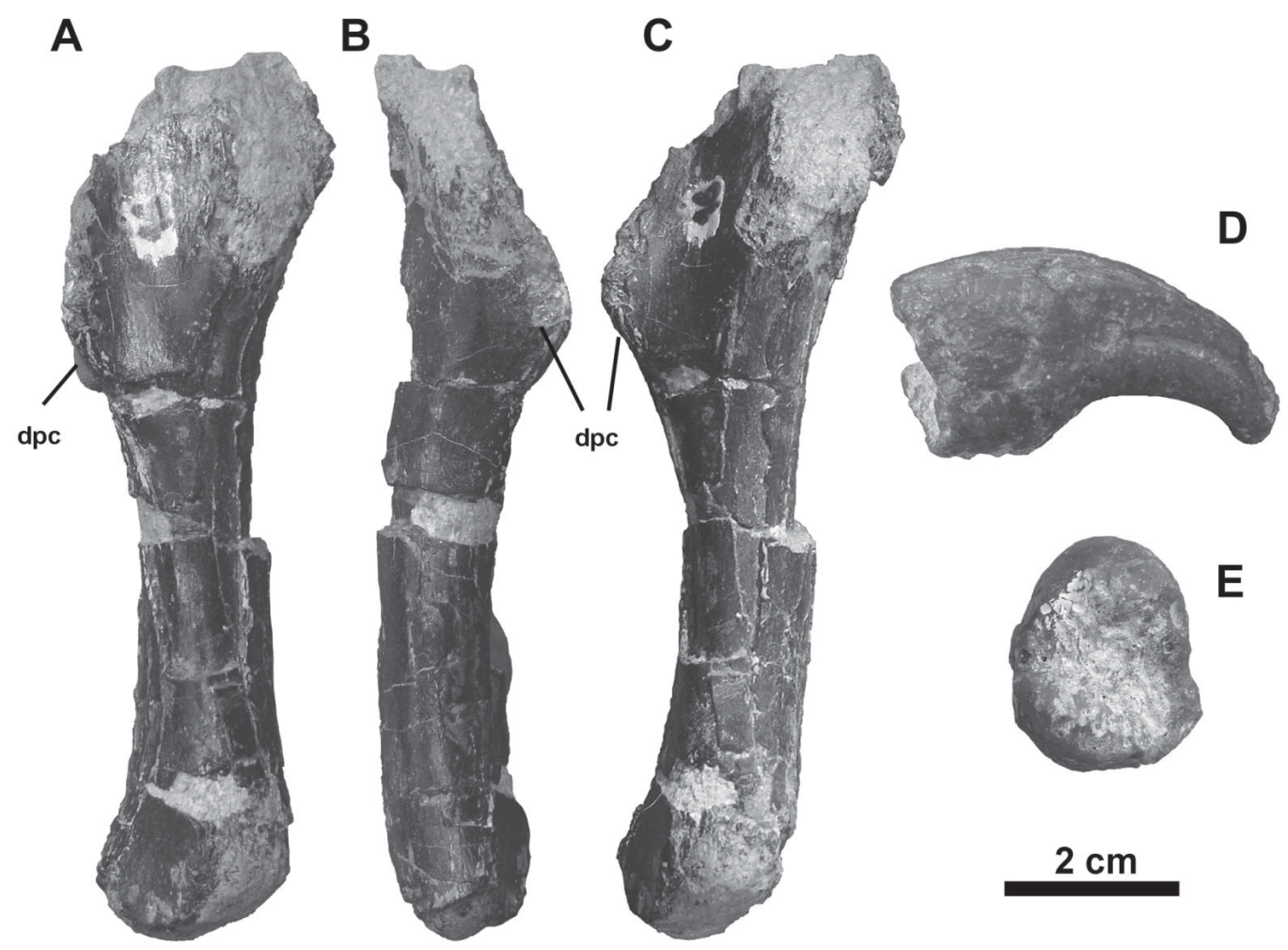

Fig. 5. Aniksosaurus darwini gen. et sp. nov. A-C, right humerus (MDT-PV 1/16) in cranial (A), lateral (B) and medial (C) views. D,E, manual ungual phalanx (MDT-PV 1/40) in side (D) and proximal (E) views. Abbreviations: dpc, deltopectoral crest.

the more conservative proportions described for Aniksosaurus.

A manual ungual phalanx, lacking part of its proximal end, is preserved (MDT-PV $1 / 40$; Fig. 5D,E). This ungual probably belongs to digit I of the manus, based on its remarkable curvature, transverse thickness, axial symmetry, and relative proportions with respect to the available humeri and ulna. However, the ungual cannot be confidently assigned to the left or to the right hand. The ungual phalanx is strongly curved in lateral view, and looks big with respect to the preserved humeri and ulna, thus suggesting that Aniksosaurus was a large-clawed animal. Proximally, the ungual phalanx is oval in cross section. The flexor tubercle is prominent and rounded in ventral view.

\section{Pelvic girdle}

The pelvic girdle of Aniksosaurus is represented by four incomplete ilia and an isolated ischium, but none of the pubes has been recovered.
Ilium. The iliac blades are broken off, excepting for some portions of the preacetabular wing. However, most of pubic and ischiadic peduncles, acetabular rim, and postacetabular wing are available, thus offering relevant information about iliac anatomy. The craniolaterally excavated pubic peduncle of one of the ilia (Fig. 6) demonstrates that a widely developed cuppedicus fossa was present, and part of its external boundary ridge is represented by a horizontal crest on the lateral surface of the preacetabular wing. The presence of a cuppedicus fossa on the ilium of Aniksosaurus constitutes a synapomorphy of Coelurosauria, as it is seen in most of its members (e.g, Ornitholestes, Tyrannosaurus, Ornithomimidae, Deinonychus), being absent in basal tetanurines (e.g., Allosaurus) and abelisauroids. The acetabulum is proportionally low, with a faint and slightly laterally projecting supracetabular crest. Thus, the acetabular roof is transversely narrow, a condition differing from that of basal Theropoda (e.g., Coelophysis, Elaphrosaurus, Allosaurus) in which the supracetabular crest is 
Table 1. Measurements (in millimeters) of selected bones of Aniksosaurus darwini gen. et sp. nov. The asterisk (*) indicate that the bone is incomplete or deformed.

\begin{tabular}{|c|c|c|c|c|c|c|}
\hline \multicolumn{4}{|c|}{ Cervical vertebra } & MDT-PV 1/14 & & \\
\hline \multicolumn{4}{|c|}{ Centrum height at the cranial articular surface } & 12 & & \\
\hline \multicolumn{4}{|c|}{ Height of the neural arch up to the spine base } & 23 & & \\
\hline \multicolumn{4}{|c|}{ Height of the neural canal } & 10 & & \\
\hline \multicolumn{4}{|c|}{ Anterior caudal vertebra } & MDT-PV 1/32 & & \\
\hline \multicolumn{4}{|c|}{ Centrum length } & 34 & & \\
\hline \multicolumn{4}{|c|}{ Centrum width } & 33 & & \\
\hline \multicolumn{4}{|c|}{ Centrum height } & 37 & & \\
\hline \multicolumn{4}{|c|}{ Total height } & 80 & & \\
\hline \multicolumn{4}{|c|}{ Middle caudal vertebra } & MDT-PV 1/13 & & \\
\hline \multicolumn{4}{|c|}{ Centrum length } & 40 & & \\
\hline \multicolumn{4}{|c|}{ Length of rhe neural arch } & 38 & & \\
\hline \multicolumn{4}{|c|}{ Total height } & $17^{*}$ & & \\
\hline \multicolumn{4}{|c|}{ MDT-PV 1/16 } & MDT-PV 1/37 & MDT-PV 1/29 & MDT-PV $1 / 42$ \\
\hline \multicolumn{2}{|l|}{ Length } & & $110^{*}$ & $?$ & $?$ & $?$ \\
\hline \multirow{2}{*}{\multicolumn{2}{|c|}{ Width of deltopectoral cres }} & & 26 & $29^{*}$ & $?$ & 22 \\
\hline & & & $30^{*}$ & $?$ & $?$ & ? \\
\hline \multirow{2}{*}{\multicolumn{2}{|c|}{ Least shaft diameter }} & & 15 & 14 & 13 & 13 \\
\hline & & & IDT-PV 1/17 & & & \\
\hline \multicolumn{2}{|l|}{ Length } & & $110^{*}$ & & & \\
\hline \multicolumn{2}{|c|}{ Proximal width } & & 25 & & & \\
\hline \multicolumn{2}{|c|}{ Least shaft diameter } & & 10 & & & \\
\hline \multicolumn{2}{|c|}{ Manual ungual phalan } & & IDT-PV $1 / 40$ & & & \\
\hline \multicolumn{2}{|l|}{ Length } & & 44 & & & \\
\hline \multicolumn{2}{|c|}{ Greatest width } & & 16 & & & \\
\hline \multicolumn{2}{|c|}{ Proximal height } & & 24 & & & \\
\hline Ilia & & & IDT-PV $1 / 33$ & MDT-PV 1/24 & & \\
\hline length & & & $165^{*}$ & $160^{*}$ & & \\
\hline Femora & & & MDT-PV $1 / 3$ & MDT-PV 1/23 & MDT-PV 1/27 & MDT-PV 1/26 \\
\hline Length & & & 247 & $204 *$ & $204 *$ & $240^{*}$ \\
\hline Least sh & aft diameter & & 27 & 21 & 27 & 29 \\
\hline Proxim & I width & & 60 & $?$ & $?$ & $?$ \\
\hline Ischium & & & IDT-PV 1/41 & & & \\
\hline Preserv & $\mathrm{d}$ length & & 75 & & & \\
\hline Probabl & length & & 160 & & & \\
\hline Tibiae & MDT-PV & MDT-PV & MDT-PV & MDT-PV & MDT-PV & MDT-PV \\
\hline & $1 / 1$ & $1 / 2$ & $1 / 10$ & $1 / 22$ & $1 / 28$ & $1 / 34$ \\
\hline length & $?$ & $245^{*}$ & $?$ & $270^{*}$ & $?$ & 250 \\
\hline least width & 17 & 21 & 18 & 22 & 20 & 19 \\
\hline
\end{tabular}

laterally prominent, and is similar to the more derived condition of coelurosaurs in which this crest is reduced. Moreover, the supracetabular crest of Aniksosaurus is less well developed than in the basal maniraptoran Ornitholestes. The pubic peduncle of ilium is craniocaudally elongate and has a triangular cross-section, as is usual in Tetanurae. The ischiadic peduncle is smaller, and part of the antitrochanter is discernible on one of the ilia (MDT-PV 35). The antithrochanter is craniocaudally convex and placed more laterally than the pubic peduncle. The postacetabular blade is craniocaudally elongate, and its lateral surface is convex, reflecting the existence of a well developed ventral fossa for the M. caudifemoralis brevis. The brevis fossa expands transversely towards the rear, depicting a paddle-shaped contour in ventral view. The brevis fossa is bounded laterally by a prominent and markedly expanded brevis shelf, which is quadrangular in lateral view (Fig. 6A). The brevis fossa is also limited by a medial shelf (which articulates with the sacral ribs), extending parallel to the brevis shelf, although it is less well developed than the latter structure. 
Table 2. Measurements (in millimeters) of holotype specimen of Aniksosaurus darwini gen. et $s p$. nov. The asterisk $\left(^{*}\right)$ indicate that the bone is incomplete or deformed.

\begin{tabular}{lcc}
\hline & Length & Least width of shaft \\
\hline Femur & $204^{*}$ & 20 \\
Tibia & $245^{*}$ & 23 \\
Fibula & $225^{*}$ & 4 \\
Mtt II & 98 & 10 \\
Mtt III & 124 & 10 \\
Mtt IV & 105 & 9 \\
Ph I-1 & 16 & \\
Ph I-2 & 15 & \\
Ph II-1 & 31 & \\
Ph II-2 & 21 & \\
Ph III-1 & 33 & \\
Ph III-2 & 30 & \\
Ph IV-1 & 22 & \\
Ph IV-2 & 16 & \\
Ph IV-3 & 15 & \\
\hline
\end{tabular}

Ischium. This bone (MDT-PV 1/41) lacks a good part of its cranial border and almost all the distal part of the shaft. The preserved portions of ischium indicate this bone was long and slender, transversely flattened and slightly curved medially. The acetabular surface is represented by a proximal emargination, being caudally bounded by an enlarged, transversely thick iliac peduncle. The rest of the preserved ischium indicates that the obturator process and pubic peduncle (both broken) appear to have been platelike. The shaft is transversely almost flattened, with its external surface convex.

\section{Hindlimb}

Femur. Five femora have been recovered from the quarry, the best preserved of which is MDT-PV 1/3 (Fig.7). The femur of Aniksosaurus is stout, closely resembling the proportions of Allosaurus (Gilmore, 1920; Madsen, 1976). The femoral head is transversely elongate and craniomedially projected. The anterior trochanter is wing-shaped and separated from the greater trochanter by a deep cleft, which is narrower than that on the femur of Allosaurus. The anterior trochanter is more proximally projected than in Allosaurus, reaching a level slightly ventral to the greater trochanter. The anterior trochanter has a marked bulge (accessory trochanter; Hutchinson, 2001) at the base of its cranial margin, as it is seen in Tyrannosaurus, for example. The greater trochanter is similar to those of Tyrannosaurus and Ornithomimidae (Osmólska et al., 1972) in being craniocaudally expanded, constituting a derived coelurosaurian condition different from that of Allosaurus and more basal theropods (e.g., abelisauroids, coelophysoids) in which the greater trochanter is craniocaudally narrower. Distal to the greater trochanter, there is a small but deep elliptical depression near the caudal margin of the lateral surface of femur, which may represents the site of insertion of the M. ischiotrochantericus (Fig. 7B, istr; Hutchinson, 2001). This feature does not seem as well-developed in smaller specimens. The elliptical depression mentioned above is present, but less marked, in Piatnitzkysaurus and probably in Ceratosaurus (Gilmore, 1920) and Tyrannosaurus (Osborn, 1906).

The fourth trochanter is not complete on any of the femora, but the information taken together from several specimens indicates that it was not prominent, although it was proximodistally very extensive reaching the middle of the shaft. There is a marked muscular trace on the medial surface of the femoral shaft, immediately cranial to the fourth trochanter. This depression is deep and semicircular in contour, and corresponds to the insertion of the M.caudifemoralis longus (e.g., Hutchinson, 2001). This depression is as deep as in Allosaurus (Madsen, 1976), Sinraptor (Currie \& Zhao, 1993), and Gorgosaurus (Lambe, 1914), thus contrasting with the condition present in adult specimens of derived coelurosaurs (e.g., ornithomimids, oviraptorans, dromaeosaurids) in which such depression is almost absent.

The femoral shaft is curved in lateral view and triangular in transverse section with the apex projecting cranially. A nutrient foramen perforates the proximal third of the shaft on its cranial surface, as in Allosaurus. A sharp and rugose ridge extends along the craniomedial edge of the distal shaft, bounding the adductor fossa present on the medial surface of the femoral shaft. However, the adductor fossa is not as deep as in other theropods such as Allosaurus, Sinraptor, Tyrannosaurus and Gallimimus, for example.

Distally, the femur is transversely wide, with well-defined articular condyles. The extensor groove is weakly defined on the craniodistal surface of the femur, a condition that differs from that of Piatnitzkysaurus, Sinraptor, Allosaurus or Tyrannosaurus in which this groove is deep. The tibial condyle is transversally narrow, proximodistally low and craniocaudally wide, with a flattened distal articular surface. The fibular condyle is conical, craniocaudally short, and more distally projected than the tibial condyle. 


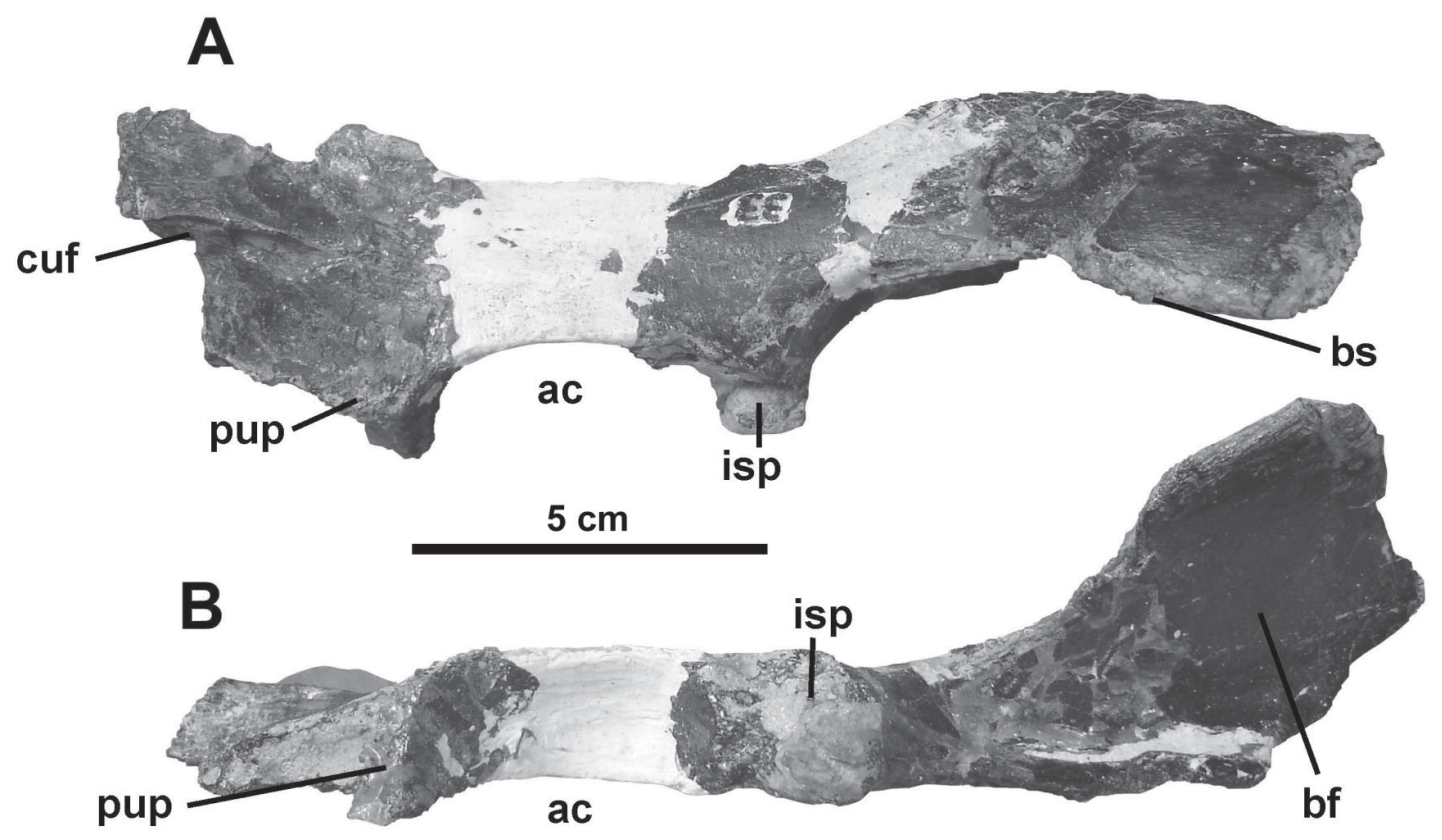

Fig. 6. Aniksosaurus darwini gen. et sp. nov. Left ilium in lateral (A) and ventral (B) views. Abbreviations: ac, acetabulum; bf, brevis fossa; bs, brevis shelf; cuf, fossa cuppedicus; isp, ischiadic peduncle; pup, pubic peduncle.

The ectocondylar tuberosity, although incomplete in all the femora, is triangular in cross-section, being proximodistally high and transversely narrow. Between the ectocondylar tuber and the tibial condyle there is a deep, wide, and triangular popliteal fossa, with a weak circular depression in its proximal portion. The shape of this fossa and the presence of the circular depression at its proximal portion are similar to the condition in Allosaurus. The fibular condyle is proximodistally high, approximately the same height caudally as the ectocondylar tuberosity. The lateral surface of the fibular condyle has a number of well-marked striations similar to those in Allosaurus.

Tibia. Seven tibiae are available. The tibia is long and slender, and based on the holotype specimen (MDT-PV 1/50; Fig.8), it is longer (by approximately $20 \%$ ) than the respective femur. However, the tibia of Aniksosaurus is notably more robust and proportionally shorter than in Coelurus (Carpenter et al., 2005), in which this bone is slender and considerably more elongate respect to femur length. The cnemial crest of the tibia of Aniksosaurus looks prominent, but its incomplete state in all of the available tibiae precludes comparisons of its development (e.g., degree of cranial and proximal projection) to other theropods. The fibular crest is represented by a sharp, longitudinally extensive and laterally directed flange, restricted to the proximal third of the tibia, being intermediate in lateral outgrowth between the robust and conspicuous one of Allosaurus and the less marked of Deinonychus. A foramen is present on the lateral face of the shaft, distal to the fibular crest. The tibial shaft is almost straight in lateral view, but slightly curved (i.e., laterally convex) in cranial aspect. Most of the cranial surface of the shaft is flattened, and along its outer side there is a distinct facet for articulation with the fibula. The fibular crest is connected with the outer malleolus of distal tibia through a sharp lateral margin.

Distally, the end of the tibia is moderately expanded transversely and it is not flared medially and laterally to the degree observed in Allosaurus, for example. The distal end is craniocaudally compressed and triangular in distal view. The depression for reception of the ascending proccess of astragalus is craniocaudally shallow and describes a proximodistally high and transversely wide subtriangular contour, indicative that this part of the astragalus (not preserved) was scale-like and well developed. Aniksosaurus differs from Allosaurus in that the flange that abuts against the proximal edge of the ascending proccess of astragalus is almost absent. Moreover, the internal border of the ar- 

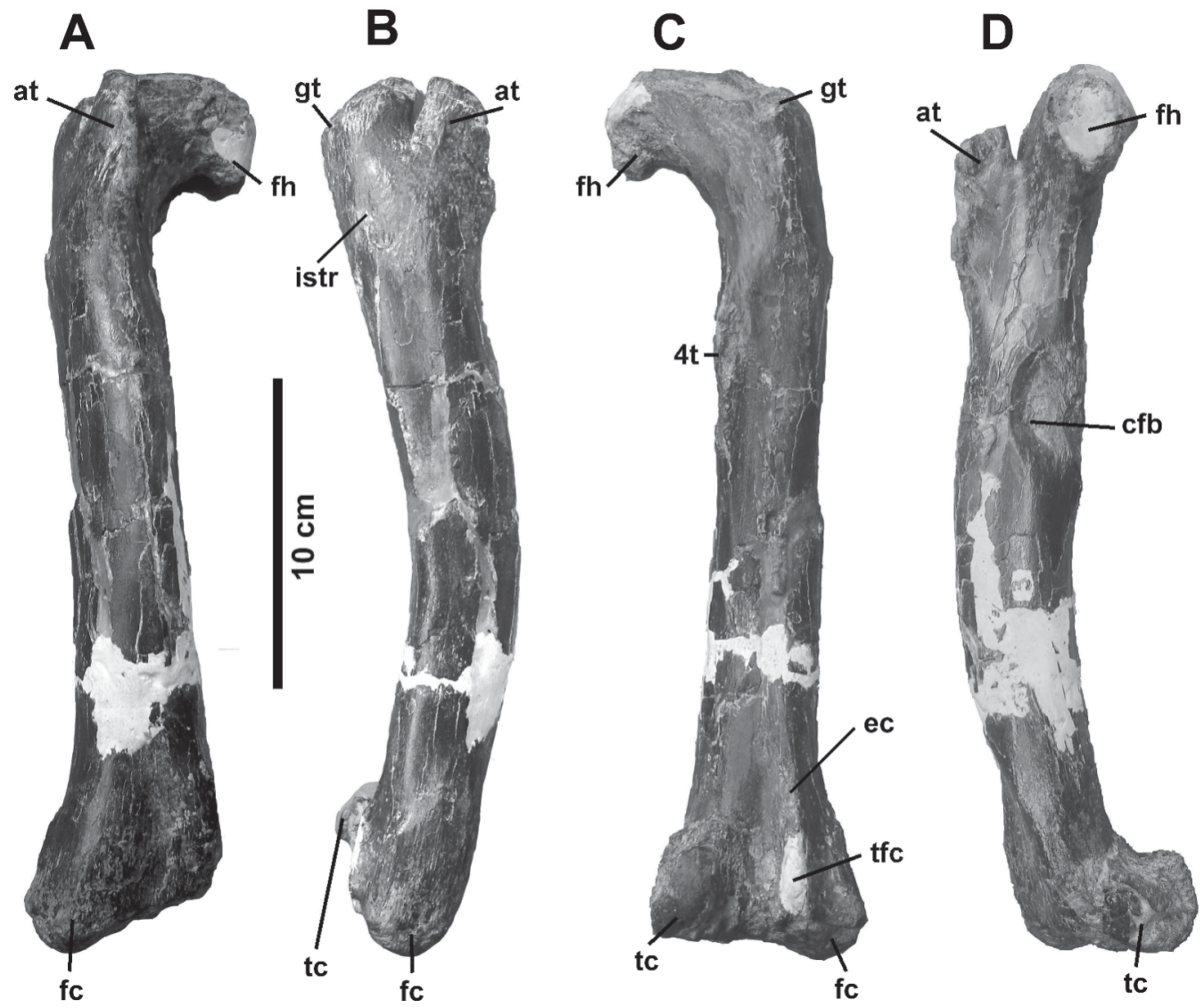

Fig. 7. Aniksosaurus darwini gen. et sp. nov. Right femur in cranial (A), lateral (B), caudal (C) and medial (D) views. Abbreviations: at, anterior trochanter; $\mathrm{cfb}$, insertion of M. caudifemoralis brevis; ec, ectocondylar tuberosity; fc, fibular condyle; $4 \mathrm{t}$, fourth trochanter; gt, greater trochanter; istr, insertion of M.ischiotrochantericus; tc, tibial condyle.

ticular facet for reception of the ascending astragalar process approaches the medial edge of the inner malleolus more closely than in Allosaurus, indicating that the ascending process of astragalus in Aniksosaurus was transversely wider than in basal theropods (e.g., Allosaurus, Sinraptor).

The lateral malleolus of the distal tibia is more prominent than the medial one, and exhibits a transversely convex cranial facet for articulation with the distal extremity of fibula. In distal view, the tibia depicts a subtriangular contour, with concave both cranial and caudal margins and the outer malleolus curved and projected caudally.

Fibula. Only the right fibula (MDT-PV 1/49) of the holotype has been preserved. It is proximally incomplete and its shaft is somewhat deformed. It is a very long and thin bone, much more slender than in Allosaurus, being similar to that of coelurosaurian theropods (e.g., Coelurus, Gallimimus; Rauhut, 2003). Its proximal region is craniocaudally expanded and medially excavated, but state of preservation avoids to estimate its depth and extension. Unlike other theropods, a «biceps tubercle» (i.e., the site of insertion of the M. iliofibularis) is not obvious. The distal expansion of the fibula for articulation with the tarsus is reduced, also indicating a reduced fibular facet on both calcaneum and astragalus.

Metatarsals and phalanges. A well-preserved, articulated right foot is available (MDTPV 1/51; Fig. 9). The proximal and distal ends of metatarsals I, III and IV are slightly eroded, and the ungual phalanx of digit 2 and the three distal phalanges of digit 3 are not preserved. The foot is approximately symmetrical, with metatarsal III being the longest and metatarsals II and IV virtually equal in length. Metatarsal III 


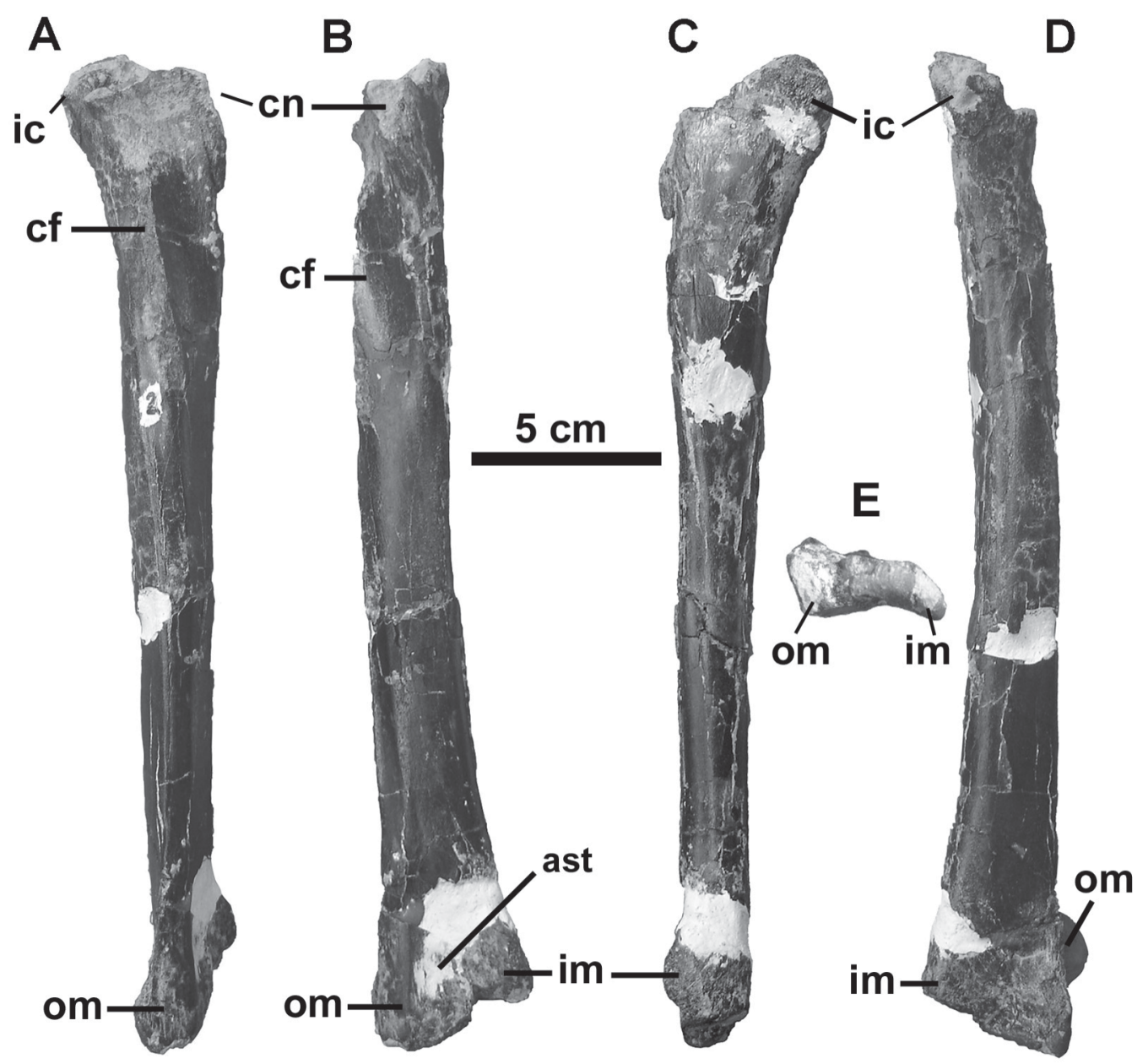

Fig. 8. Aniksosaurus darwini gen. et sp. nov. Right tibia (MDT-PV 1/50) in lateral (A), cranial (B), medial (C), caudal (D) and distal (E) views. Abbreviations: ast, astragalar depression; cf, crista fibularis; cn, cnemial crest; ic, inner condyle of proximal tibia; im, inner malleolus; om, outer malleolus.

roughly represents $50 \%$ of tibial length (ratio based on measurements of the holotype specimen). The metatarsals are proportionally robust and subcylindrical in cross-section. In general, the foot of Aniksosaurus looks more robust than in Ornitholestes (Carpenter et al., 2005), especially the pedal phalanges which in the later taxon are longer and more slender than in the Patagonian taxon. The same observation also applies for Coelurus (Carpenter et al., 2005) which exhibits very elongate metatarsals, even more than in Ornitholestes.

A fragment of metatarsal I has been preserved attached to the caudolateral half of metatarsal II. Metatarsal I exhibits a ginglymoid distal articulation with a deep wide lateral ligament pit. Metatarsal II is straight in cranial view, becoming transversely broader towards the distal end. It is mediolaterally compressed along the proximal half, but subtriangular in cross-section distally. It is sigmoid (i.e., caudal convexity) in side view. The distal articulation is partially damaged, but it is documented the presence of a deep medial ligament pit. Metatarsal III is straight in cranial view and its shaft becomes transversely broader towards its distal extremity. Its proximal end is craniocaudally expanded, thus forming triangular surfaces for the articulation with the proximal extremities of both metatarsal II and IV. As seen in proximal aspect, the countour of metatarsal III is tear-shaped, being transversely wider cranially than caudally. However, this metatarsal apparently lacks the «hour-glass» shape present among basal teta- 


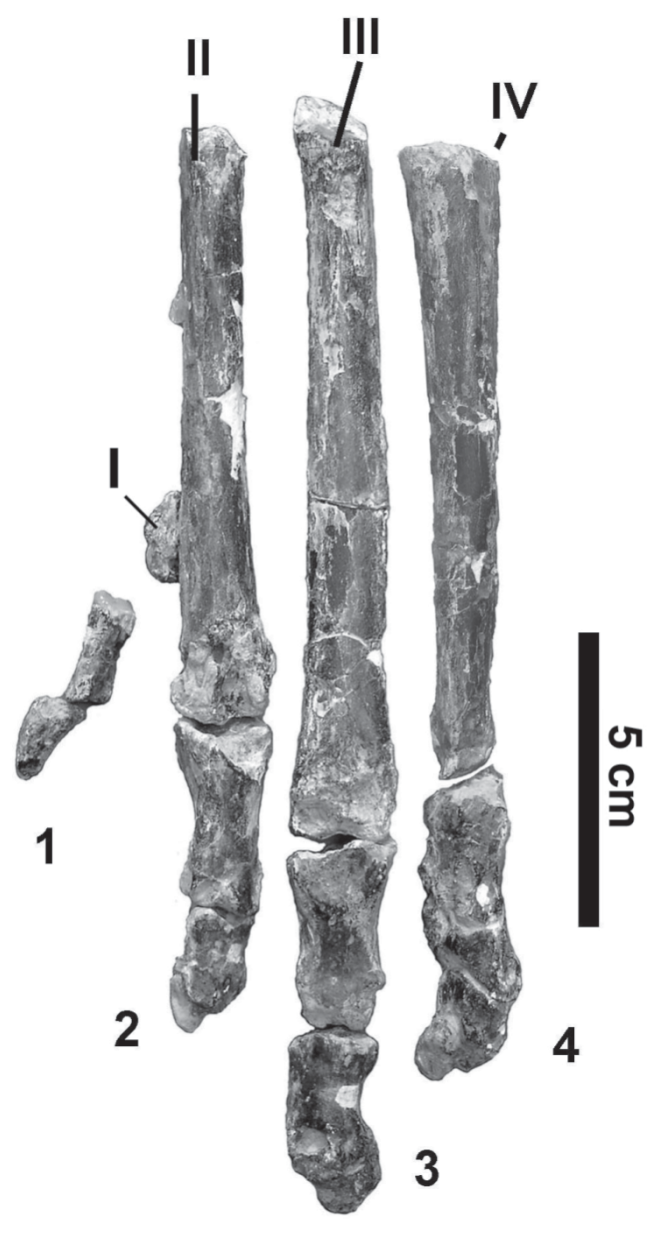

Fig. 9. Aniksosaurus darwini gen. et sp. nov. Right foot in cranial view. Abbreviations: 1-4, digits 1 to 4 ; I-IV, metatarsals I to IV.

nurans (e.g., Piatnitzkysaurus, Sinraptor, Allosaurus, Ornitholestes, Tanycolagreus). The cranial surface of metatarsal III is transversely convex on its proximally third, becoming flat on the rest of the bone. The medial and lateral surfaces of metatarsal III are nearly flat, but the medial surface for articulation with metatarsal II is slightly grooved longitudinally, thus sharply distinguishing from the caudal surface of metatarsal III. Moreover, the medial facet for metatarsal II exhibits a well defined distal margin, thus clearly separating from the medial surface of distal ginglymoid. The caudal surface of metatarsal II is almost flat, except for its distal third, which is slightly notched both medially and laterally. Such medial and lateral concavities create the room for the distal articulations of metatarsals II and IV, respectively, when the metatarsals are articulated. As a result, the caudal surface of metatarsal III describes a slight longitudinal ridge between the aforementioned concavities. Such construction of metatarsal III differs from that of Allosaurus (Madsen, 1976). In contrast, the metatarsal III of Aniksosaurus resembles (albeit it is not identical to) the condition present among derived coelurosaurians (e.g., Neuquenraptor). Finally, in contrast to Allosaurus, Megaraptor, and Fukuiraptor, in which the caudal surface of distal articulation is strongly excavated and bounded by a pair of longitudinal ridges, in Aniksosaurus this surface is almost flat. The distal articulation of metatarsal III has a wide cranial excavation for extensor ligament, as well as deep collateral ligament pits.

Metatarsal IV is nearly straight in cranial view. In proximal view it has a subtriangular outline with a caudomedial projection for articulation with metatarsal III, that is similar to but less developed than those present in Piatnitzkysaurus, Sinraptor, Allosaurus and Ornitholestes. The caudal surface of metatarsal IV is almost flat, especially over its proximal two thirds. The distal half of the medial face of the shaft is marked by a diagonal groove directed caudodistally. The distal third of the bone thins transversely, roughly representing half the transverse width of metatarsal III. This condition differs from the other tetanurans (e.g., Allosaurus, Sinraptor, Gallimimus, Ornitholestes, Deinonychus, Sinornithoides) in which the distal end of metatarsal IV is unreduced.

Pedal phalanges. The proximal phalanges are longer than the distal phalanges. All of the proximal phalanges have their distal ends slightly craniocaudally and transversely expanded. Ventrally the phalanges are quite flat, more than in Allosaurus, Sinraptor or Deinonychus. The ungual phalanx of digit 1 is subtriangular and lateromedially compressed with a lateral groove. There is no groove on the medial surface.

\section{CHARACTER ANALYSIS}

Aniksosaurus distinguishes from other theropods by the following combination of features:

1) Caudal cervicals with elevated neural arch pedicles. The base of the neural arch in the caudal cervical vertebrae is not dorsoventrally higher than the vertebral centrum in Ceratosauria, Allosaurus, Tyrannosauridae, Gallimimus, Ornitholestes and Deinonychus. In Aniksosaurus, however, the base of the neural arch is 2.5 times the height of the centrum.

2) Wide neural canal on caudal cervical vertebrae. In Aniksosaurus the neural canal is 
wide and elliptical, with a vertical longest axis of the ellipse being dorsoventrally oriented. The neural canal is proportionally small in relation to the vertebral centrum and the base of the neural arch in Sinraptor, Allosaurus, Gallimimus. and Deinonychus, for example. The neural canal is also large in Coelurus (Carpenter et al., 2005) and Avimimus (Kurzanov, 1987) although it is not elliptical but square. Wheter this feature of Aniksosaurus was related with allometric changes during ontogeny remains unknown.

3) Cranial caudals with saggital ventral keel. There is a longitudinal ventral groove on the cranial caudal centra of many theropods: Dilophosaurus, Ceratosaurus, Carnotaurus, Torvosaurus, Piatnitzkysaurus, Sinraptor, Allosaurus, Gallimimus, Ornitholestes, Coelurus, Deinonychus and Alvarezsauridae (Bonaparte, 1991; Bonaparte et al., 1990; Britt, 1991; Carpenter et al., 2005; Currie \& Zhao, 1993; Madsen, 1976; Novas 1997; Osmólska et al, 1972; Ostrom, 1969). In this context, the single saggital keel present in the proximal caudals of Aniksosaurus is tentatively interpreted as an autapomorphic feature of this taxon, pending on more information about the distribution of this character within Tetanurae.

4) Robust manual unguals. In most theropods, the manual ungual phalanges are strongly compressed transversely. The height to width ratio of the articular surface of the manual ungual phalanges is 1.54 for Tarbosaurus, 1.58 for Dilophosaurus, 1.6 for Sinraptor, 1.83 for Allosaurus and 2.34 for Deinonychus (Maleev, 1955; Welles, 1984; Currie \& Zhao, 1993; Gilmore, 1920; Ostrom, 1969). Conversely, the ratio in Aniksosaurus is 1.1, thus demonstrating the presence of manual unguals of heavy construction, which look large when compared with any of the preserved long bones (e.g., humeri, ulna, femora, tibiae) of this taxon. In contrast, the manus of Coelurus (Carpenter et al., 2005) and Tanycolagreus (Carpenter et al., 2005) are delicate and slender, in sharp contrast with the robust construction of the manus of Aniksosaurus inferred on the basis of its ponderous ungual. The robust condition of the ungual phalanges of Aniksosaurus remembers some ornithomimids and alvarezsaurids, in which the height to width ratio is lower than 1.5 (P. Makovicky, pers. comm). However, manual unguals of these two derived coelurosaurians clades are not trenchant and curved as in Aniksosaurus.

5) Brevis shelf of the ilium extremely expanded and projected lateroventrally. In theropods, the brevis shelf is a well developed ridge oriented ventrolaterally, serving as exter- nal boundary of the brevis fossa. In ventral view the brevis fossa is rectangular-shaped, even in Ceratosaurus (Gilmore, 1920) and abelisaurids (e.g., Carnotaurus; Bonaparte et al., 1990) in which the brevis shelf is well developed. Moderately expanded brevis shelves are documented in Dilophosaurus, Piatnitzkysaurus, Allosaurus, Sinraptor, and basal coelurosaurs such as Ornitholestes, Tyrannosaurus and Ornithomimus (in some derived maniraptorans, such as the dromaeosaurid Deinonychus, a wing-like brevis shelf is absent on the caudolateral portion of the ilium; Novas, 1996). Aniksosaurus clearly distinguishes from theropods mentioned above in that the caudal half of brevis shelf is strongly projected outside, thus resulting in a fan-shaped expansion in ventral view. Interestingly, the condition described for Aniksosaurus is reminiscent of that in the alvarezsaurid Shuuvuia deserti (Chiappe et al., 2002) as well as the flightless Cretaceous bird Patagopteryx deferrarisi (Alvarenga \& Bonaparte, 1992).

6) Caudolateral surface of proximal femur with strong depression and rugosities presumably for the attachment for $M$. ischiotrochantericus. On the caudolateral surface of proximal femur, Aniksosaurus has a strong semilunar bulge, delimiting a well-marked depression on some femora, which presumably served for the attachment of the M. ischiotrochantericus (Hutchinson, 2001). On the contrary, such depression is absent in ceratosaurians (e.g., Ceratosaurus, Carnotaurus, Xenotarsosaurus), basal tetanurans (e.g., Piatnitzkysaurus, Allosaurus), and coelurosaurians (e.g., Tyrannosaurus, Gallimimus, Deinonychus).

7) Metatarsal IV and its digit transversely narrow. In most theropods, the distal end of the metatarsal IV is less expanded transversely than those of metatarsals II and III. Nevertheless, the distal reduction of metatarsal IV is much more marked in Aniksosaurus than in other theropods. The ratio of the distal width of metatarsal III with respect to the distal width of metatarsal IV is 1.57 in Dilophosaurus, 1.37 in Allosaurus, 1.16 in Sinraptor, 0.85 in Gallimimus, and 1.14 in Deinonychus (Welles, 1984; Gilmore, 1920; Currie \& Zhao, 1993; Osmólska et al, 1972; Ostrom, 1969). In Aniksosaurus, the ratio is 2.14. In congruence with the reduction of metatarsal IV, its correspondent digit is also constricted transversely, but without loss of phalanges: phalanx 2 of digit 4 in Aniksosaurus has a transverse width of $9 \mathrm{~mm}$, representing $75 \%$ of the thickness of phalanx 2 of digit $2(12 \mathrm{~mm})$ and slightly less than $70 \%$ of phalanx 2 of digit $3(13 \mathrm{~mm})$. In contrast, digit 4 is equal or subequal to digit 2 in 
transverse width in Dilophosaurus, Allosaurus and Deinonychus. Digit 4 is lateromedially thicker than digit 2 in Sinraptor and Gallimimus. Digit 4 is also thicker than digit 3 in the troodontid Borogovia (Osmólska, 1987). The condition described above for Aniksosaurus resembles that of ceratosaurians (e.g., Ceratosaurus, abelisauroids), in which metatarsal III and its digit is transversely wider than metatarsals II and IV and their digits, condition that may have evolved convergently in Aniksosaurus and ceratosaurians.

\section{DISCUSSION}

Aniksosaurus was discovered in the same formation were several remains of abelisauroid theropods have been found (e.g., Xenotarsosaurus bonapartei, as well as an isolated maxilla and vertebrae referred to Abelisauridae indet.; Martínez et al., 1986, 2004; Lammana et al., 2002). Although it is appropriate to ask if Aniksosaurus is a member of this group of dinosaurs, we did not identify abelisauroid synapomorphies in any of the preserved elements of Aniksosaurus (excepting for the narrow proportions of metatarsal IV and its digit). Moreover, comparisons with well known taxa of Abelisauroidea such as Carnotaurus (Bonaparte et al., 1990) and Masiakasaurus (Carrano et al., 2002) clearly demonstrate important distinctions with Aniksosaurus, including: 1) humerus with well defined deltopectoral crest (different from the atrophied one of abelisauroids), 2) manual unguals stoutly constructed (being distinct from the slender and reduced manual unguals of abelisauroids), 3) ilium with well developed cuppedicus fossa (which is absent among abelisauroid theropods), 4) femur with proximally projected anterior trochanter, almost reaching the level of the articular head (contrasting with the less well projected anterior trochanter present among abelisauroids), 5) greater trochanter craniocaudally expanded (different from the craniocaudally narrow one plesiomorphically retained by abelisauroids), 6) femoral head rectangular in cranial aspect (in contrast with abelisauroids in which the femoral head is bulbous and craniomedially oriented), 7) trochanteric shelf represented by a faint rugosity (different from the prominent ridge that is characteristic of abelisauroids), and 8) fibular shaft craniocaudally narrow (instead of the wider shaft retained in abelisauroids).

The anatomical characteristics enumerated above not only justify the allocation of Aniksosaurus outside of Abelisauroidea, but also support the referral of Aniksosaurus within Coelu- rosauria. For example, a transversely wide cuppedicus fossa, an anterior trochanter placed level with the greater trochanter, a reduced fourth trochanter, a poorly developed adductor fossa on the distal femur, and a reduced fibula are features shared by compsognathids, coelurids, ornithomimids, tyrannosaurids and paravians. In this context, the narrowing of metatarsal IV and its digit documented in the coelurosaurian Aniksosaurus is better interpreted as convergently evolved also in ceratosaurian theropods.

Elucidation of the phylogenetic position of Aniksosaurus among Coelurosauria is difficult to assert, mainly due to the lack of preservation of important portions of the skeleton, including the skull, manual bones and tarsus. At least, available information supports that the new Patagonian taxon is not a member of the Maniraptoriformes (sensu Holtz, 2000), a coelurosaurian subclade including Ornithomimosauria, Tyrannosauridae, Oviraptorosauria, Alvarezsauridae and Paraves, because the Patagonian taxon retains the following plesiomorphies: distal tibia with astragalar surface proportionally low, and insertion of the M. caudifemoralis longus extensive and deep.

Aniksosaurus exhibits limb bones that resemble the robust proportions seen in the basal tetanuran Allosaurus, for example, rather than the gracile and elongate ones of most coelurosaurians (e.g., Ornitholestes, Coelurus, Tanycolagreus, ornithomimosaurians, oviraptorosaurians, paravians). Although the phylogenetic significance of such limb bone proportions in theropod dinosaurs requires further exploration, the robustness of Aniksosaurus may support its basal position among coelurosaurians.

Assuming that Aniksosaurus is a basal coelurosaur, it is required to examine briefly its relationships with other representatives: Aniksosaurus resembles the compsognathid Sinosauropteryx (Currie \& Chen, 2001) and the bizarre coelurosaur Nqwebasaurus (De Klerk et al., 2000), in the robust construction of the humerus and manual unguals, although other basal tetanurans (as for example, Allosaurus, Piatnitzkysaurus, Torvosaurus) also exhibit proportionally shortened humeri and manual unguals of ponderous construction. Moreover, no distinctive features of Compsognathidae are identified in the Patagonian taxon, thus reference of Aniksosaurus to this coelurosaurian clade is untenable. Besides, no unique features are shared by Aniksosaurus with Ornitholestes and Coeluridae (including Coelurus and Tanycolaegrus).

Some features of Aniksosaurus look highly derived for a basal coelurosaurian, including a 
strongly reduced supracetabular crest (a condition that is shared with tyrannosaurids, oviraptorosaurians and paravians), and absence of a medial adductor fossa on the distal femur (derived condition shared with oviraptorosaurians, alvarezsaurids and paravians). However, the remaining available bones of Aniksosaurus do not exhibit synapomorphies of paravians or tyrannosaurids, so the condition mentioned above for the supracetabular crest and distal femur may represent independent acquisitions with respect to derived coelurosaurians.

In proximal view it is observed that metatarsal III of Aniksosaurus is not constricted (i.e., hourglass shaped) as in the basal tetanurans Sinraptor (Currie \& Zhao, 1993) and Allosaurus (Gilmore, 1920) and the basal coelurosaurians Ornitholestes and Tanycolagreus (Carpenter et $a l ., 2005)$. In contrast, the proximal extremity of metatarsal III of Aniksosaurus lacks the caudomedial hook that wraps metatarsal II caudally. Although Aniksosaurus seems more derived than some basal coelurosaurians (e.g., Ornitholestes, Tanycolagreus; Carpenter et al., 2005) with regard to the construction of the proximal metatarsus, it does not show, however, the derived pattern of arctometatarsalian theropods (e.g., ornithomimids, tyrannosaurids, elmisaurids and troodontids; Holtz, 1994). In particular, Aniksosaurus is less derived than dromaeosaurids (e.g., Deinonychus; Ostrom, 1969) in which metatarsal III is proximally compressed and the facets for articulation with metatarsal II and IV are parallel and perpendicular with respect to the transverse plane.

In sum, available information indicates that Aniksosaurus occupies a basal position within Coelurosauria, looking more derived than compsognathids, coelurids and Ornitholestes, although less derived than Maniraptoriformes. In this context, the new South American taxon is relevant, because it may represent a Late Cretaceous survivor of a poorly documented basal coelurosaurian radiation.

\section{ACKNOWLEDGMENTS}

Peter Macovicky made enlighting observations that improved the quality of the present paper. Thanks also to Leonardo Salgado for his clever observations and suggestions. Matthew Lamanna for his assistance with editing, formatting, and English grammar. Sergio Archangelsky for editorial assistance. Gabriel Casal for technical preparation of the material. Marcelo Luna for photographs and additional preparation of the specimen. We wish to express our gratitude to the following persons and institutions: Prof. Adriana Maure, Lic. Juan C.Sciutto, Mr. Alejandro Goicoechea, Government of the city of Sarmiento, and Regimiento de Infantería 25 stationed in Sarmiento. Financial support for this project was received from CONICET and Agencia Nacional de Promoción Científica y Técnica (to FEN).

\section{BIBLIOGRAPHY}

Alvarenga, H. M. F. \& J. F. Bonaparte. 1992. A new flightless land bird from the Cretaceous of Patagonia. In K. E. Campbell (ed.), Pap.Avian Paleo.Honoring Pierce Brodkorb. Nat. Hist. Mus. Los Angeles County, Sci. Ser. 36: 51-64.

Archangelsky, S., E. S. Bellosi, G. A. Jalfin \& C. Perrot. 1994. Palynology and alluvial facies from the midCretaceous of Patagonia, subsurface of San Jorge Basin, Argentina. Cret. Res. 15: 127-142.

Bonaparte, J. F. 1986. Les dinosaures (Carnosaures, Allosauridés, Sauropodes, Cetiosauridés) du Jurassique Moyen de Cerro Cóndor (Chubut, Argentine). Ann. Paléont. 72: 247-289.

1991. Los vertebrados fósiles de la Fm. Río Colorado, de la ciudad de Neuquén y cercanías, Cretácico Superior, Argentina. Rev. Mus. Arg. Cienc. Nat. «B. Rivadavia» 4: 17-123.

Bonaparte, J. F., F. E. Novas \& R. Coria. 1990. Carnotaurus sastrei Bonaparte, the horned, lightly built carnosaur from the Middle Cretaceous of Patagonia. Contr. Sci. 416: 1-42.

Bridge, J. S., G. A. Jalfin \& S. M. Georgieff. 2000. Geometry, lithofacies, and spatial distribution of Cretaceous fluvial sandstone bodies, San Jorge Basin, Argentina: Outcrop analog for the hydrocarbonbearing Chubut Group. Jour. Sed. Res. 70: 341-359.

Britt, B. 1991. Theropods of Dry Mesa Quarry (Morrison Formation, Late Jurassic), Colorado, with emphasis on the osteology of Torvosaurus tanneri. Brigham Young Univ., Geol. Stud. 37: 172.

Calvo, J. O. \& J. F. Bonaparte.1991. Andesaurus delgadoi gen. et sp. nov. (Saurischia, Sauropoda), dinosaurio Titanosauridae de la Formación Río Limay (Albiano-Cenomaniano), Neuquén, Argentina. Ameghiniana 28: 303-310.

Calvo, J. O., J. D. Porfiri, C. Veralli, F. E. Novas \& F. Poblete. 2004. Phylogenetic status of Megaraptor namunhauiquii Novas based on a new specimen from Neuquén, Patagonia, Argentina. Ameghiniana 41: 565-576.

Carpenter, K., C. Miles \& K. Cloward. 2005. New small theropod from the Upper Jurassic Morrison Formation of Wyoming. In Carpenter, K. (ed.). The Carnivorous Dinosaurs. Indiana University Press, pp. 23-48.

Carpenter, K., C. Miles , J. H. Ostrom \& K. Cloward. 2005. Redescription of the small maniraptoran theropods Ornitholestes and Coelurus from the Upper Jurassic Morrison Formation of Wyoming. In Carpenter, K. (ed.). The Carnivorous Dinosaurs. Indiana University Press, pp. 49-71. 
Carrano, M. T., S. C. Sampson \& C. A. Forster. 2002 The osteology of Masiakasaurus knopfleri, a small abelisauroid (Dinosauria: Theropoda) from the Late Cretaceous of Madagascar. Jour. Vert. Paleo. 22: 510-534.

Chiappe, L. M., M. A. Norell \& J. M. Clark. 2002. The Cretaceous, short-armed Alvarezsauridae: Mononykus and its kin. In: Chiappe, L.M. and Witmer, L. (eds.) Mesozoic Birds. Above the Heads of Dinosaurs. University of California Press, Berkeley, pp. 87-120.

Clark, G. A. Jr. 1993. Termini situm et directionem partium corporis indicantes. In Baumel, J. J., King, A. S., Breazile, J. E., Evans, H. E., Vanden Berge, J. C. (eds.). Handbook of Avian Anatomy: Nomina Anatomica Avium. Second Edition, Publication of the Nuttall Ornithological club 23: 1-6.

Colbert, E. H. 1989. The Triassic dinosaur Coelophysis. Bull.Mus.Northern Arizona Press, Series 57: 1-160.

Currie, P. J. \& X. Zhao. 1993. A new carnosaur (Dinosauria,Theropoda) from the Jurassic of Xinjiang, People's Republic of China. Can. Journ. Earth Sci. 30: 2037-2081.

Currie, P. J. \& P. Chen. 2001. Anatomy of Sinosauropteryx prima from Liaoning, northeastern China. Can. Journ. Earth Sci. 39: 1705-1727.

De Klerk, W., C. Forster, S. Sampson, A. Chinsamy \& C. Ross. 2000. A new coelurosaurian dinosaur from the Early Cretaceous of South Africa. Journ.Vert. Paleo. 20: 324-332.

Frankfurt, N. G. \& L. M. Chiappe. 1999. A possible oviraptorosaur from the Late Cretaceous of Northwestern Argentina. Jour. Vert. Paleont. 19: 101-105.

Gilmore, C. 1920. Osteology of the carnivorous Dinosauria in the United States National Museum, with special reference to the genera Antrodemus (Allosaurus) and Ceratosaurus. Bull. U.S. Nat. Mus. 110: $1-154$.

Heinrich, R., C. Ruff, \& D. Weishampel. 1993. Femoral ontogeny and locomotor biomechanics of Dryosaurus lettowvorbecki (Dinosauria: Iguanodontia). Zool. Journ. Linn. Soc. 108: 179-196.

Holtz, T. 1994. The arctometatarsalian pes, an unusual structure of the metatarsus of Cretaceous Theropoda (Dinosauria: Saurischia). Journ. Vert. Pal. 14: 480-519.

- 2000. A new phylogeny of the carnivorous dinosaurs. Gaia 15:5-61.

Holtz, T, R. E. Molnar \& P. J. Currie. 2004. Basal Tetanurae. In: The Dinosauria (Second Edition), Weishampel, D.B., Dodson, P., and Osmolska, H. (eds.), California University Press, pp. 71-110.

Hutchinson, J. R. 2001. The evolution of femoral osteaology and soft tissues on the line of extant birds (Neornithes). Zool. Jour. Linn. Soc. 131: 169:197.

Kellner, A. W. A. 1999. Short note on a new dinosaur (Theropoda, Coelurosauria) from the Santana Formation (Romualdo Member, Albian) northeastern Brazil. Bol. Mus. Nac. N.S. 49: 1-8. Rio de Janeiro. 2001. New information on the theropod dinosaurs from the Santana Formation (Aptian-Albian), Araripe Basin, northeastern Brazil. Journ. Vert. Paleont. 21(Suppl. 3): 67A.
Kurzanov, S. M. 1987. Avimimids and the problem of the origin of birds. Sovm. Sov.-Mong. Paleontol. Eksped. Trudy 31: 5-95. (In Russian).

Lamanna, M., R. Martínez \& J. Smith. 2002. A definitive abelisaurid theropod dinosaur from the Early Late Cretaceous of Patagonia. Journ.Vert. Paleo. 22: 58-69.

Lambe, L. M. 1914. On a new genus and species of carnivorous dinosaur from the Belly River Formation of Alberta with a description of the skull of Stephanosaurus marginatus from the same horizon. Ottawa Nat. 28: 13-20.

Madsen, J. 1976. Allosaurus fragilis: a revised osteology. Utah Geol. Min. Surv. Bull. 1091: 1-163.

Makovicky, P., S. Apesteguía, \& F. Agnolín. 2005. The earliest dromaeosaurid theropod from South America. Nature 437: 1007-1011.

Maleev, E. A. 1955. New carnivorous dinosaurs from the Upper Cretaceous of Mongolia. Doklady Akad. Nauk S.S.S.R. 104: 779-783. (In Russian)

Martínez, R.1998a. Notohypsilophodon comodorensis gen. et sp. nov., un Hypsilophodontidae (Ornithischia: Ornithopoda) del Cretácico Superior de Chubut, Patagonia Central, Argentina. Acta Geológica Leopoldensia 21: 119-135.

1998b. An articulated skull and neck of Sauropoda from the Upper Cretaceous of central Patagonia, Argentina. Journ. Vert. Paleo. 18: 61A.

- 1999. Un cráneo y cuello articulados de Sauropoda (Dinosauria: Saurischia) del Cretácico Superior de Chubut. Ameghiniana 36: 105R.

Martínez, R. \& F. E. Novas. 1997. Un nuevo tetanuro (Dinosauria: Theropoda) de la Fm. Bajo Barreal (Cretácico superior) Patagonia. Ameghiniana 34: 538.

Martínez, R., F. E. Novas \& A. Ambrosio. 2004. Abelisaurid remains (Theropoda, Ceratosauria) from Southern Patagonia. Ameghiniana 41: 577-585.

Martínez, R., O. Giménez, J. Rodríguez \& G. Bochatey. 1986. Xenotarsosaururs bonapartei nov. gen. et sp. (Carnosauria, Abelisauridae), un nuevo Theropoda de la Formación Bajo Barreal, Chubut Argentina. IV Congreso Argentino de Paleontologia y Bioestratigrafía 2: 23-31.

Martínez, R., O. Giménez, J. Rodríguez \& M. Luna. 1989. Un titanosaurio articulado del género Epachthosaurus, de la Formación Bajo Barreal. Cretácico del Chubut. Ameghiniana 26: 246R.

Martínez, R., O. Giménez, J. Rodríguez, M. Luna \& M. Lamanna. 2004. An articulated specimen of the basal titanosaurian (Dinosauria:Sauropoda) Epachthosaurus sciuttoi from the early Late Cretaceous Bajo Barreal Formation of Chubut Province, Argentina. Journ. Vert. Paleo. 24: 107-120.

Martínez, R., M. Lamanna, J. Smith, G. Casal \& M. Luna. 1999. New Cretaceous theropod material from Patagonia. Jour. Vert. Paleo. 19: 62 A.

Martínez, R., A. Maure, M. Oliva \& M. Luna. 1993. Un maxilar de Theropoda (Abelisauria) de la Formación Bajo Barreal, Cretácico Tardío, Chubut, Argentina. Ameghiniana 30: 109-110.

Naish, D., D. M. Martill \& E. Frey. 2004. Ecology, systematics and biogeographical relationships of di- 
nosaurs, including a new theropod, from the Santana Formation (?Albian, Early Cretaceous) of Brazil. Historical Biology 1-14.

Novas, F. E. 1996. Alvarezsauridae, Cretaceous maniraptorans from Patagonia and Mongolia. Queensland Mus. Mem. 31: 320-351.

- 1997. Anatomy of Patagonykus puertai (Theropoda, Avialae, Alvarezsauridae), from the Late Cretaceous of Patagonia. Jour. Vert. Paleo. 17: 137-166.

- 1998. Megaraptor namunhuaiquii gen. et sp. nov., a large-clawed, Late Cretaceous Theropod from Argentina. Jour. Vert. Paleo. 18: 4-9.

- 2003. Avian traits in the ilium of Unenlagia comahuensis (Maniraptora: Avialae). In: Currie, P.J., Koppelhus, E.B., Shugar, M.A. \& Wright, J.L (eds.). Feathered Dragons: Studies on the Transition from Dinosaurs to Birds, pp. 150-166.

Novas, F. E. \& F. Agnolín. 2004. Unquillosaurus ceibali Powell, a giant maniraptoran (Dinosauria, Theropoda) from the Late Cretaceous of Argentina. Rev. Mus. Arg. Cienc. Nat. n. s. 6: 61-66.

Novas, F. E., L. C. Borges Ribeiro \& I. de Souza Carvalho. 2005. Maniraptoran theropod unqual from the Marilia Formation (upper Cretaceous), Brazil. Rev. Mus. Arg. Cienc. Nat. n. s. 7: 31-36.

Novas, F. E., M. Ezcurra \& F. Agnolín. 2006. Humerus of a basal abelisauroid theropod from the Late Cretaceous of Patagonia. Rev. Mus. Arg. Cienc. Nat. n. s. 8: 63-68.

Novas, F. E. \& D. Pol. 2005. New evidence on deinonychosaurian dinosaurs from the Late Cretaceous of Patagonia. Nature 433: 858-861.

Novas, F. E. \& P. Puerta. 1997. New evidence concerning avian origins from the Late Cretaceous of Patagonia. Nature 387: 390-392.

Osborn, H. F. 1906. Tyrannosaurus, Upper Cretaceous Carnivorous Dinosaur (Second communication). Bull. Amer. Mus. Nat. Hist. 22: 281-296.

- 1917. Skeletal adaptations of Ornitholestes,
Struthiomimus and Tyrannosaurus. Bull. Amer. Mus. Nat. Hist. 35: 733-771.

Osmólska, H. 1987. Borogovia gracilicrus gen. et sp. $n$., a new troodontid dinosaur from the Late Cretaceous of Mongolia. Acta Paleont. Pol. 32: 133-150.

Osmólska, H., E. Roniewicz \& R. Barsbold. 1972. A new dinosaur Gallimimus bullatus n. gen. n. sp. (Ornithomimidae) from the Upper Cretaceous of Mongolia. Palaeont. Pol. 27: 103-143.

Ostrom, J. 1969. Osteology of Deinonychus antirrhopus, an unusual Theropod from the Lower Cretaceous of Montana. Peabody Mus. Nat. Hist. Bull. 30: 1-165.

Powell, J. 1986. Revisión de los titanosauridos de América del Sur. Tesis Doctoral. Universidad Nacional de Tucumán.

- 1990. Epachthosaurus sciuttoi gen. et. sp. nov., un nuevo dinosaurio sauropodo del Cretácico de Patagonia (Provincia del Chubut, Argentina). Actas V Cong. Arg. Paleo. Bioestrat. 1: 123-128.

Powell, J., O. Giménez, R. Martínez \& J. Rodriguez. 1989. Hallazgo de saurópodos en la Formación Bajo Barreal de Ocho Hermanos, Sierra de San Bernardo, Provincia del Chubut (Argentina) y su significado cronológico. Anais XI Cong. Brasileiro Paleo. Curitiba, 165-176.

Raath, M. A.1977. The Anatomy of the Triassic Theropoda Syntarsus rhodesiensis (Saurischia: Podokesauridae) and a Consideration of its Biology. Unpublished Ph.D. thesis, Grahamstown, S.Africa: Rhodes University.

Rauhut, O. W. M. 2003. The interrelationships and evolution of basal theropod dinosaurs. Spec. Pap. Palaeont. 69: 1-213.

Sciutto, J. \& R. Martínez.1994. Un nuevo yacimiento fosilífero de la Fm. Bajo Barreal (Cretácico tardío) y su fauna de saurópodos. Naturalia Patagonica 2: 27-47.

Welles, S. 1984. Dilophosaurus wetherilli (Dinosauria, Theropoda). Osteology and comparisons. Palaeontographica A 185: 85-180. 